\title{
Overexpression of nucleostemin contributes to an advanced malignant phenotype and a poor prognosis in oral squamous cell carcinoma
}

\author{
R Yoshida ${ }^{1,3}$, H Nakayama*,1,3, M Nagata ${ }^{1}$, A Hirosue ${ }^{1}$, T Tanaka $^{1}$, K Kawahara ${ }^{1}$, Y Nakagawa ${ }^{1}$, Y Matsuoka $^{1}$, \\ J Sakata ${ }^{1}, \mathrm{H} \mathrm{Arita}^{1}$, A Hiraki ${ }^{1}$, M Shinohara ${ }^{1}$ and T Ito $^{2}$ \\ ${ }^{1}$ Department of Oral and Maxillofacial Surgery, Kumamoto University Graduate School of Life Sciences, Honjo 1-1-1, Chuo-ku, \\ Kumamoto 860-8556, Japan and ${ }^{2}$ Department of Pathology and Experimental Medicine, Kumamoto University Graduate School of \\ Life Sciences, Honjo 1-1-1, Chuo-ku, Kumamoto 860-8556, Japan
}

Background: Nucleostemin (NS) is essential for the maintenance of stem cell properties, the functions of which remain poorly understood in cancer cells. The purpose of this study was to explore the impact of NS on malignancy and its clinical significance in oral squamous cell carcinoma (OSCC) patients.

Methods: We investigated the effects of NS on the proliferation and invasion of OSCC using NS-overexpressing or -knockdown OSCC cells. We assessed the activation of the STAT3 (signal transducer and activator of transcription 3) signalling pathway and the downstream targets in the cells with different expression levels of NS. An immunohistochemical analysis of NS was also performed in 54 OSCC patients who were treated with preoperative chemoradiotherapy and surgery.

Results: The overexpression of NS significantly enhanced the proliferation and invasive potential of OSCC cells. On the other hand, downregulation of NS suppressed the invasiveness of the cells. The alterations of these malignant phenotypes were associated with the activation of STAT3 signalling and its downstream targets. An immunohistochemical analysis demonstrated that a high NS tumour expression level significantly correlated with an advanced T-stage and N-stage. Furthermore, a Cox regression analysis revealed that the NS status (hazard ratio, 9.09; $P=0.002$ ) was a significant progression factor for OSCC patients.

Conclusions: Our results suggest that targeting NS may provide a promising treatment for highly malignant OSCC.

Oral cancer is one of the most common cancers worldwide (Platz et al, 1985; Laramore et al, 1992; Siegel et al, 2012), and the survival rate of patients with oral cancer has not improved despite improvements and innovations in diagnostic techniques and treatments (Gupta et al, 2009). The high malignant potential of oral squamous cell carcinoma (OSCC), including the advanced tumour size and presence of nodal metastasis at the time of diagnosis, affect the patient survival. Abnormal proliferation and enhanced invasion and metastasis are important hallmarks of cancer (Hanahan and Weinberg, 2011), and these biological behaviours define the malignant phenotypes of OSCC. Therefore, to elucidate the crucial molecular mechanisms associated with the malignant phenotypes of OSCC will be helpful for the development of more effective treatments to improve the patient survival.

Nucleostemin (NS) is a nucleolar GTP-binding protein that is expressed in the nucleolus and is involved in pre-rRNA processing, ribosome synthesis and genome protection (Zhu et al, 2006; Romanova et al, 2009; Meng et al, 2011; Lin et al, 2014).

\footnotetext{
*Correspondence: Dr H Nakayama; E-mail: hinakayam@gmail.com
}

${ }^{3}$ These authors contributed equally to this work.

Received 23 May 2014; revised 12 August 2014; accepted 16 September 2014; published online 14 October 2014 (c) 2014 Cancer Research UK. All rights reserved 0007-0920/14 
Nucleostemin has been reported to have an important role in the maintenance of stem cell properties in rat neural stem cells (Tsai and McKay, 2002), and to be expressed in different types of cancer cell lines, including renal cancer and oesophageal cancer (Fan et al, 2006; Nakajima et al, 2012). On the other hand, there have been few studies that have investigated the clinical and biological significance of NS in cases with head and neck carcinoma, including OSCC (Cada et al, 2007). We have previously reported that NS was expressed in neoplastic oral tissue, and that it was associated with proliferation in OSCC cell lines (Yoshida et al, 2011). However, the biological impact of NS on the malignant phenotypes of OSCC and the clinical significance of NS in patients with OSCC have not been fully clarified.

One of the most recognised signalling pathways associated with the malignant progression of tumours involves the signal transducer and activator of transcription 3 (STAT3) (Devarajan and Huang, 2009). Signal transducer and activator of transcription 3 has been shown to have a crucial role in cancer metastasis by transcriptionally regulating the expression of genes that promote cell proliferation, cell survival, invasion, angiogenesis and tumour immune evasion (Huang, 2007). Signal transducer and activator of transcription 3 is known to be activated by many cytokines, growth factors and oncogenic proteins, and overexpression of activated (phosphorylated) p-STAT3 has been reported to be correlated with increased malignancy and a worse prognosis of patients with OSCC (Shinriki et al, 2009; Macha et al, 2011). On the other hand, little is known about the association between NS and the STAT3 signalling pathway.

In the present study, to explore the biological impact of NS on the malignant progression of OSCC, we established two NSoverexpressing OSCC cell lines, and found that an overexpression of NS contributes to enhanced cellular proliferation and invasion of the cells via the activation of STAT3 signalling. Furthermore, an immunohistochemical analysis using OSCC patient tissue samples demonstrated that a high NS tumour expression level was significantly correlated with advanced $\mathrm{T}$-stage, $\mathrm{N}$-stage and a poor prognosis.

\section{MATERIALS AND METHODS}

Cell lines. A human OSCC cell line derived from a tongue tumour, SAS, (Okumura et al, 1996) was obtained from the RIKEN BioResource Center (Ibaraki, Japan). Human OSCC cell lines, OSC-20 and HOC-313, were kindly donated by the Department of Oral and Maxillofacial Surgery, Kanazawa University Graduate School of Medical Science. Previous in vitro and in vivo experiments have shown that HOC-313 cells possess more invasive properties than OSC-20 cells (Matsumoto et al, 1989). All cell lines were cultured in Dulbecco's modified Eagle's medium (DMEM; Gibco, Grand Island, NY, USA) with $10 \%$ fetal bovine serum (FBS). The cells were incubated at $37^{\circ} \mathrm{C}$ in a $5 \% \mathrm{CO}_{2}$ atmosphere with saturated humidity.

Plasmids. The human NS expression plasmid, pMY-NS-IRESGFP, was obtained from Dr Atsushi Hirao (Division of Molecular Genetics, Center for Cancer and Stem Cell Research, Cancer Research Institute, Kanazawa University). The human NS cDNA was inserted into the pMY-IRES-GFP vector.

Stable cell lines. pMY-IRES-GFP vectors were transfected into a Plat-E packaging cell line (a kind gift from Dr Toshio Kitamura, The Institute of Medical Science, The University of Tokyo) using FuGENE 6 (Roche Diagnostics, Indianapolis, IN, USA) to obtain $v s$. Oral squamous cell carcinoma cells $\left(2 \times 10^{5}\right.$ cells $)$ were infected with viruses. Cells were washed three times with phosphatebuffered saline, resuspended in DMEM containing 10\% FBS and analysed for GFP fluorescence on a FACS Aria II (BD Biosciences,
Tokyo, Japan) instrument. Then, infectants were fractionated according to the GFP fluorescence intensity. The fractionated cells that showed weak GFP fluorescence were designated as GFP ( - ) cells, whereas those that showed strong GFP fluorescence were designated as GFP $(++)$. Finally, stable cell lines were established by using the limiting dilution technique.

Transfection with small interfering RNA. HOC-313 cells were used in this experiment. Twenty-four hours before small interfering RNA (siRNA) transfection, the cells were diluted in fresh medium without antibiotics and were transferred to $60-\mathrm{mm}$ dishes (Nunc, Waltham, MA, USA). The cells were grown and transfected with NS-specific siRNA and Stealth RNAi Universal negative control (40 nM, Stealth siRNA, Invitrogen, Carlsbad, CA, USA) using Lipofectamine RNAi MAX (Invitrogen), as described in the manufacturer's instructions. The sequences for siRNA were as follows: for NS, sense strand $5^{\prime}$-UCGCAUUGACCAUUCAACUG GUGG-3', antisense strand 5'-CCACCAGUUUGAAUGGUC AAU- $3^{\prime}$ (named NS1), and sense strand $5^{\prime}$-UCGCAUUGACCAUU CAACUGGUGG- ${ }^{\prime}$, antisense strand $5^{\prime}$-CCACCAGUUUGAAUG GUCAAU-3' (named NS2). The cells were harvested $48 \mathrm{~h}$ after transfection for a western blot analysis.

Cell proliferation analysis. Cell proliferation was determined using the cell proliferation reagent, WST-8 (Cell Counting Kit-8, Dojindo, Kumamoto, Japan). Briefly, $2 \times 10^{3}$ cells were seeded into 96-well plates in $100 \mu \mathrm{l}$ of medium in triplicate for each condition. Every $24 \mathrm{~h}$ after incubation, the WST-8 reagent was added to each well at a 1:10 dilution, and the plates were incubated for an additional $2 \mathrm{~h}$ at $37^{\circ} \mathrm{C}$. The absorbance of the samples was measured at $690 \mathrm{~nm} / 480 \mathrm{~nm}$. Each experiment was performed in triplicate.

Matrigel cell invasion assay. The cell invasion activity was measured with the Bio Coat Matrigel Invasion Chamber (Becton Dickinson, Tokyo, Japan) according to the manufacturer's protocol. Oral squamous cell carcinoma cells with the indicated status or under specific conditions were inoculated on the Matrigel-coated side of the culture inserts (upper chamber) at a density of $2 \times 10^{5}$ cells per $500 \mu \mathrm{l}$ of serum-free DMEM, and were incubated for $24 \mathrm{~h}$ at $37^{\circ} \mathrm{C}$ in a $5 \% \mathrm{CO}_{2}$ atmosphere. At the end of the incubation, the cells on the upper surface of the filter were completely removed with cotton swabs. The invaded cells that remained on the lower surface of the filter were fixed with methanol and stained with Diff-Quick (Sysmex, Hyogo, Japan). The numbers of stained cells in five randomly selected microscopic fields $(\times 200)$ per filter were counted. The experiments were repeated at least three separate times to confirm the reproducibility.

RNA isolation, reverse transcription and quantitative real-time PCR. Total RNA was isolated using the RNeasy Mini Kit (Qiagen, Tokyo, Japan). The RNA quantity, purity and integrity were evaluated using a NanoDrop spectrophotometer (Thermo Fisher Scientific Inc., Waltham, MA, USA). Complementary DNA was synthesised from total RNA using the Rever Tra Ace qPCR RT Master Mix with gDNA Remover (Toyobo Life Science, Osaka, Japan). For quantitative real-time reverse transcription-PCR (qRT-PCR), each reaction mixture was diluted five-fold with DNase-/RNase-free water (Invitrogen), and $4 \mu \mathrm{l}$ of each mixture were subjected to PCR. The reactions were run using THUNDERBIRD SYBR qPCR Mix (Toyobo Life Science) on a Light Cycler 1.5 instrument (Roche Diagnostics, Basel, Switzerland). The comparative $C_{\mathrm{t}}\left(\Delta \Delta C_{\mathrm{t}}\right)$ method was used to determine the fold changes in expression using $G A P D H$ for normalisation. Each sample was run in triplicate. The following primers were used: NS (forward: 5'-AAGCCAAGTCGGGCAAACA-3'; reverse: 5'-ACCTCTAGGAC AACATCGGAG-3'); CCND1 (forward: $5^{\prime}$ - TGGAGCCCGTGAA AAAGAGC-3'; reverse: $5^{\prime}$-TCTCCTTCATCTTAGAGGCCAC-3'); 
MMP-7 (forward: 5'-GAGTGAGCTACAGTGGGAACA-3'; reverse: 5'-CTATGACGCGGGAGTTTAACAT-3'); GAPDH (forward: $5^{\prime}$-TGTTGCCATCAATGACCCCTT-3'; reverse: $5^{\prime}$-CTCCACGAC GTACTCAGCG-3'). The cycling conditions were as follows: initial denaturation at $98^{\circ} \mathrm{C}$ for $5 \mathrm{~min}$, followed by 45 cycles at $98^{\circ} \mathrm{C}$ for $15 \mathrm{~s}, 60^{\circ} \mathrm{C}$ for $30 \mathrm{~s}$ and $72{ }^{\circ} \mathrm{C}$ for $60 \mathrm{~s}$. The experiments were performed in triplicate.

Western blot analysis. The cells were lysed on ice in $150 \mathrm{~mm}$ $\mathrm{NaCl}, 1 \%$ Triton $\mathrm{X}-100,0.5 \%$ sodium deoxycholate, $0.1 \%$ SDS, $1 \mathrm{~mm}$ EDTA-2Na of pH 8.0, 1 mм EGTA of pH 7.5, 2.5 mm sodium pyrophosphate, $1 \mathrm{~mm} \beta$-glycerophosphate, $1 \mathrm{mM} \mathrm{Na}_{2} \mathrm{VO}_{4}, 1 \mathrm{~mm}$ PMSF and $20 \mathrm{~mm}$ Tris- $\mathrm{HCl}$ of $\mathrm{pH} 7.5$ containing a protease inhibitor cocktail (Roche Diagnostics, Basel, Switzerland). Protein concentrations were determined using the BCA assay (Bio-Rad Laboratories, Hercules, CA, USA). Samples were boiled with Laemmli buffer, then equal amounts of protein were electrophoresed on polyacrylamide gels containing $0.1 \%$ SDS and then were transferred to PVDF membranes (Millipore, Hamburg, Germany). Proteins were detected using appropriate horseradish peroxidase (HRP)-conjugated secondary antibodies and an enhanced chemiluminescence substrate (Amersham Pharmacia Biotech, Buckinghamshire, UK). Proteins were detected using the following antibodies: NS (R\&D Systems, Abingdon, UK), phosphoSTAT3 (Tyr705) rabbit monoclonal antibodies (D3A7; Cell Signaling Technology, Danvers, MA, USA), phospho-STAT3 (Ser727) rabbit monoclonal antibodies (6E4; Cell Signaling Technology), STAT3 (79D7; Cell Signaling Technology) and $\beta$-actin (AC-74; Sigma-Aldrich, St Louis, MO, USA).

Patients and tissue specimens. For the clinicopathological analysis, primary oral cancer tissue samples were obtained from 54 patients with advanced OSCC treated at Kumamoto University Hospital between October 2003 and January 2009. All patients were preoperatively treated with a total of $30 \mathrm{~Gy}$ of concurrent 5-FU-based chemoradiotherapy before undergoing curative surgery. Radiotherapy was administered at a daily dose of $2.0 \mathrm{~Gy}$ five times a week for 15 days. An oral fluorouracil anticancer agent, S-1, was concurrently administered at a dose of 80,100 or $120 \mathrm{mg}$ per day according to the patient's body surface area for 14 days from the initiation of radiotherapy. All tumours were staged according to the TNM classification of the UICC (2002), and the degree of differentiation was determined according to the grade classification of the WHO. The samples were fixed with $10 \%$ formalin and embedded in paraffin. The study followed the guidelines of the Ethics Committee of Kumamoto University. The nature and aims of the study were explained to all patients, who gave their informed consent for the research.

Immunohistochemical staining and evaluation. Tissue samples obtained from biopsy specimens before preoperative chemoradiotherapy were used for the immunohistochemical analyses. The histological responses to chemoradiotherapy were graded according to the criteria proposed by Shimosato et al (1971) using specimens obtained during surgery. Formalin-fixed paraffinembedded specimens were cut into $4-\mu \mathrm{m}$ sections and mounted on MAS-GP-coated slides (Matunami Glass Ind., Ltd, Osaka, Japan). After deparaffinisation and rehydration, the sections were heated in an autoclave in $0.01 \mathrm{moll}^{-1}$ citrate buffer ( $\mathrm{pH}$ 7.0) for $15 \mathrm{~min}$ at $121^{\circ} \mathrm{C}$ for antigen retrieval. The sections were incubated with $0.3 \% \mathrm{H}_{2} \mathrm{O}_{2}$ in absolute methanol for $30 \mathrm{~min}$ to block the endogeneous peroxidase activity. Then, the sections were incubated with Protein Block Serum Free Reagent (Dako, Glostrup, Denmark) for $15 \mathrm{~min}$ to block nonspecific staining.

After the blocking step was completed, the sections were incubated with antibodies against NS (R\&D Systems) at $4{ }^{\circ} \mathrm{C}$ overnight. This was followed by sequential $60 \mathrm{~min}$ incubations with the secondary antibodies (EnVision + System-HRP Labelled
Polymer, Dako), and visualisation with the Liquid DAB + Substrate Chromogen System (Dako). All slides were lightly counterstained with haematoxylin for $30 \mathrm{~s}$ before dehydration and mounting. The expression of NS was considered to be positive when cells showed nucleolar staining. Phosphorylated STAT3 (Cell Signaling Technology) was considered to be positive when cells displayed nuclear staining. The number of NS-positive cells out of 100 cells observed in five random fields $(\times 200)$ was counted. A labelling index (LI) for NS was calculated by dividing the number of positive cells by the total number of cells per case and multiplying by 100 . The slides were independently reviewed by two researchers until a consensus was reached.

Statistical analysis. The differences in the mean values between two groups were statistically analysed using Student's $t$-test, whereas the differences in the mean values among multiple groups were analysed using a one-way ANOVA with the Bonferroni/Dunn test. To analyse the NS expression in the tissue specimens, the $\chi^{2}$-test was used to determine the associations between the NS expression status and clinical parameters. Fisher's exact test was used when one or more cells had expected values $<5$. The survival analysis was performed according to the Kaplan-Meier method. The log-rank test was used to determine the correlation of the NS expression status with the patient survival. A multivariate survival analysis was performed using the Cox regression model to study the effects of NS expression on the OS. All $P$-values were based on two-tailed statistical analyses, and $P$-values $<0.05$ were considered to be statistically significant $\left({ }^{\star} P<0.05\right.$ and $\left.{ }^{* *} P<0.01\right)$. All statistical analyses were performed using the JMP 9 software programme (SAS Institute Inc, Cary, NC, USA).

\section{RESULTS}

Establishment of NS-overexpressing OSCC cell lines. To investigate the role of NS in the malignant phenotype of cultured OSCC cell lines, we established NS-overexpressing OSCC cell lines by using a reporter system, where the NS promoter drives GFP expression, as described previously (Tamase et al, 2009). The fractionated cells that showed weak GFP fluorescence were designated as GFP $(-)$ cells, whereas those that showed strong GFP fluorescence were designated as GFP $(++)$. The expression level of GFP $(-)$ cells was approximately equal to the basal level of NS expressed in the original parent cells (data not shown). The GFP $(++)$ cells expressed a much higher level of NS compared with the control GFP $(-)$ cells (Figure 1A). Under normal culture conditions, no significant morphological differences were observed between NS-GFP $(-)$ and $(++)$ cells in the SAS cell lines. On the other hand, NS-GFP $(++)$ cells showed subtle morphological changes compared with NS-GFP ( - ) cells in the OSC-20 cell lines. The expression status of NS in each fractionated cell type was confirmed by real-time RT-PCR (Figure 1B). Finally, we named the GFP $(-)$ cells harbouring endogenous NS expression 'NS-GFP $(-)^{\prime}$ and the NS-overexpressing GFP $(++)$ cells 'NS-GFP $(++)^{\prime}$.

Effects of NS on the proliferation and invasion of OSCC cell lines. To determine whether overexpression of NS affects the growth of OSCC cells, we examined the proliferation activity of NS-low and -high cells by using the WST-8 assay. SAS/NS-GFP $(++)$ cells exhibited significantly enhanced cell proliferation compared with the SAS/NS-GFP $(-)$ cells. Increased cellular proliferation was also observed in the OSC-20/NS-GFP $(++)$ cells (Figure 2A; $P$-values $<0.05$ and $<0.01$ ).

To examine whether the expression levels of NS affect the invasiveness of OSCC cells, we examined the invasion activity of NS-GFP $(-)$ and NS-GFP $(++)$ cells using a Matrigel invasion assay system. Enhanced tumour cell invasion was observed in the 
A
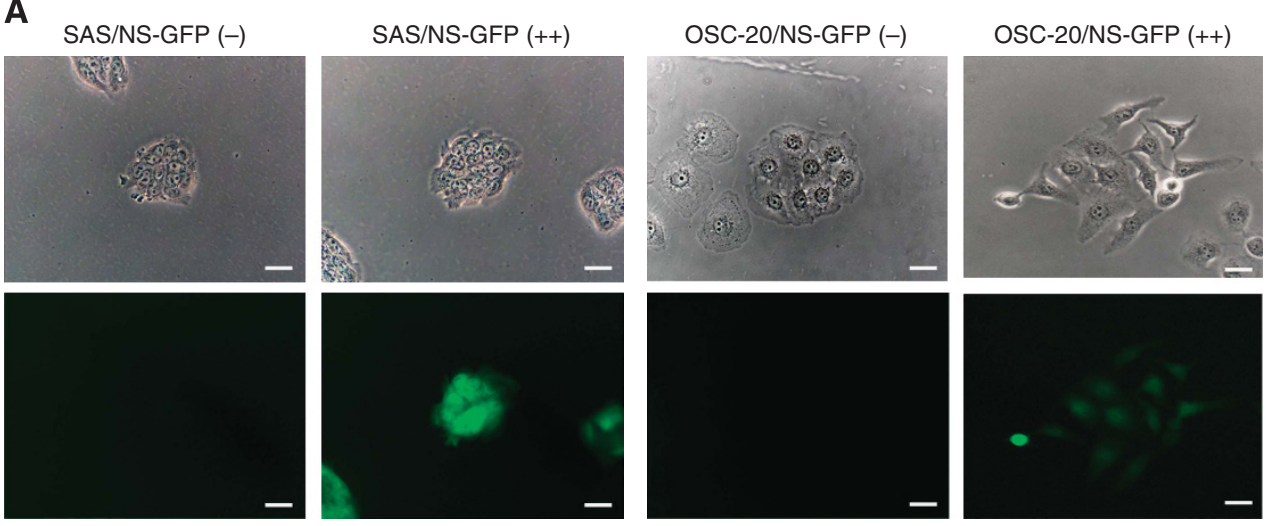

B
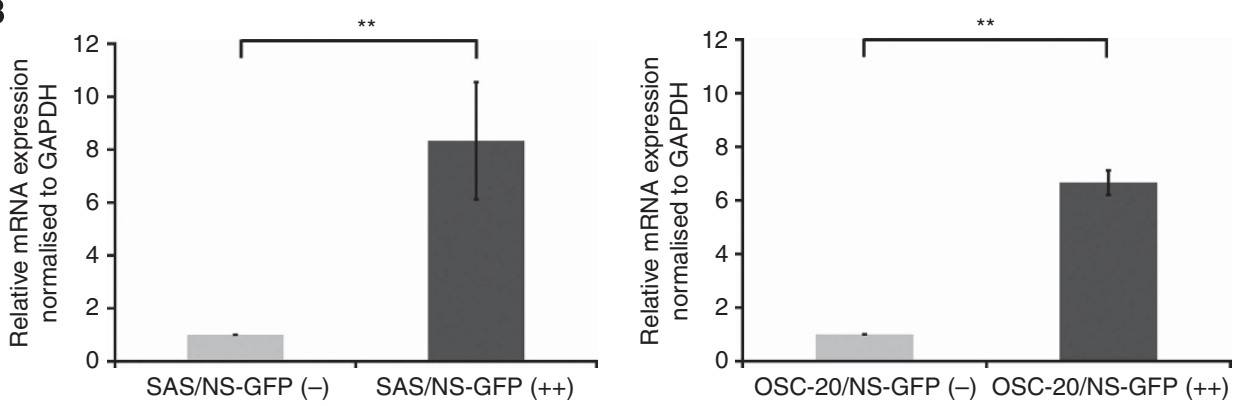

Figure 1. Photographs and NS mRNA expression in NS-overexpressing OSCC cell lines. (A) Images of the SAS and OSC-20 sublines obtained by phase-contrast microscopy (upper panel). The expression of GFP was visualised by fluorescence microscopy (lower panel). Scale bars, $20 \mu \mathrm{m}$. (B) The mRNA level of NS in each of the cell lines. Cells were harvested and the total RNA was extracted at the same time. The expression level of NS was measured using qRT-PCR. The values are expressed as the means \pm s.d. of triplicate samples. The statistical analysis was done using Student's t-test. ${ }^{\star \star} P<0.01$

NS-GFP $(++)$ cells in both the SAS and OSC-20 cells (Figure 2B; $P$-values $<0.05$ and 0.01$)$. On the other hand, downregulation of NS by siRNA led to an inverse phenomenon. HOC-313, an OSCC cell line that has high invasion activity (Yokoyama et al, 2001), showed a significant reduction of invasiveness when the endogenous NS was knocked down (Figure 2C; $P<0.01$ ). These results suggest that NS has an important role in not only the proliferation but also in the invasion of OSCC.

STAT3 signalling contributes to the regulation of the NS-dependent malignant phenotype in OSCC. To identify the signalling pathway associated with the NS-driven enhancement of cell proliferation and invasion, we investigated the involvement of the STAT3 signalling pathway. Overexpression of NS in OSC-20 cells led to a significant increase in the expression of the tyrosine phosphorylated form of STAT3 (Figure 3A). On the other hand, the downregulation of NS in HOC-313 cells significantly decreased this phosphorylation (Figure $3 \mathrm{~A}$ ). In addition, there was a positive correlation between the expressions of NS and that of tyrosine-pSTAT3 in the clinical samples of OSCC patients (Figure 3B). Furthermore, to determine the downstream targets of the STAT3 signalling pathway, we investigated the alterations in STAT3related molecules using qRT-PCR. The mRNA expression levels of CCND1 and MMP-7, molecules that regulate cell proliferation and invasion, respectively, were affected by the level of NS expression (Figure 3C). A positive correlation was observed between the expression of NS and MMP-7 in the clinical samples of OSCC patients (Supplementary Figure S1). These data suggest that NS may regulate the malignant phenotypes, such as enhanced cell proliferation and invasion, in OSCC via the STAT3 signalling pathway.

Clinical significance of NS expression in the tumours of OSCC patients. To elucidate the clinical significance of NS expression in the tumours of OSCC patients, an immunohistochemical analysis of NS was performed on biopsy specimens from 54 OSCC patients. The clinicopathological details of the patients are shown in Table 1. The patients were divided two groups (NS high and NS low) according to the LI of NS. Of the 54 OSCCs we studied, there were 19 (35.2\%) NS-high and 35 (64.8\%) NS-low OSCCs. There were no significant differences in the expression status of NS according to age, gender, the primary tumour site, clinical stage or differentiation. The frequency of NS high tumours was significantly higher in cases who showed an advanced T-stage and N-stage $(P=0.026$ and 0.024$)$. In addition, the survival rate of NS-high expression cases was significantly lower than that of NS-low expression cases (Figure 4; $P=0.018$ ). A multivariate analysis using the Cox regression model revealed that the NS expression status (hazard ratio 9.09; $P=0.002$ ) was a significant prognostic factor for the survival of OSCC patients (Table 2).

\section{DISCUSSION}

In the present study, we investigated whether the expression levels of NS affect the malignant behaviours of tumours and the clinical outcomes of OSCC patients. Our data demonstrated that NS regulates the proliferation and invasion of OSCC cells, at least partially via the activation of the STAT3 signalling pathway, and that the tumour expression status of NS is associated with the overall survival in OSCC patients (Figure 4 and Table 2). To the best of our knowledge, no other reports have demonstrated the contribution of the tumour NS expression to both malignant behaviours and the prognosis in patients with OSCC.

The importance of NS in cell proliferation, including the property of self-renewal, has been reported in several different 

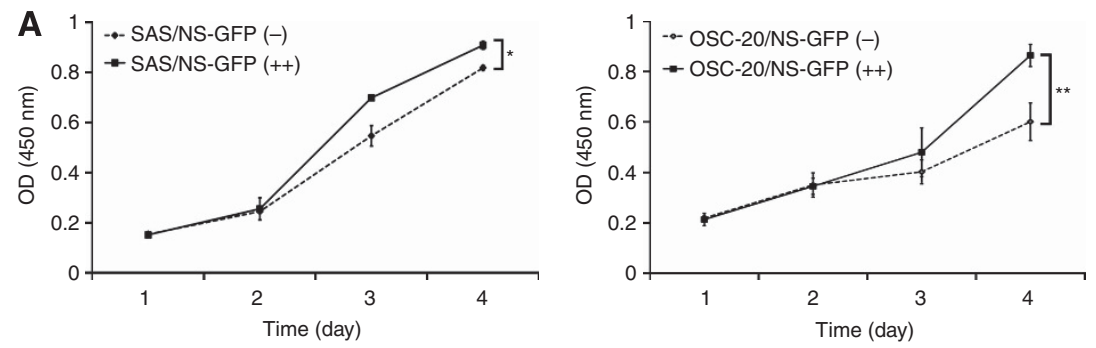

B
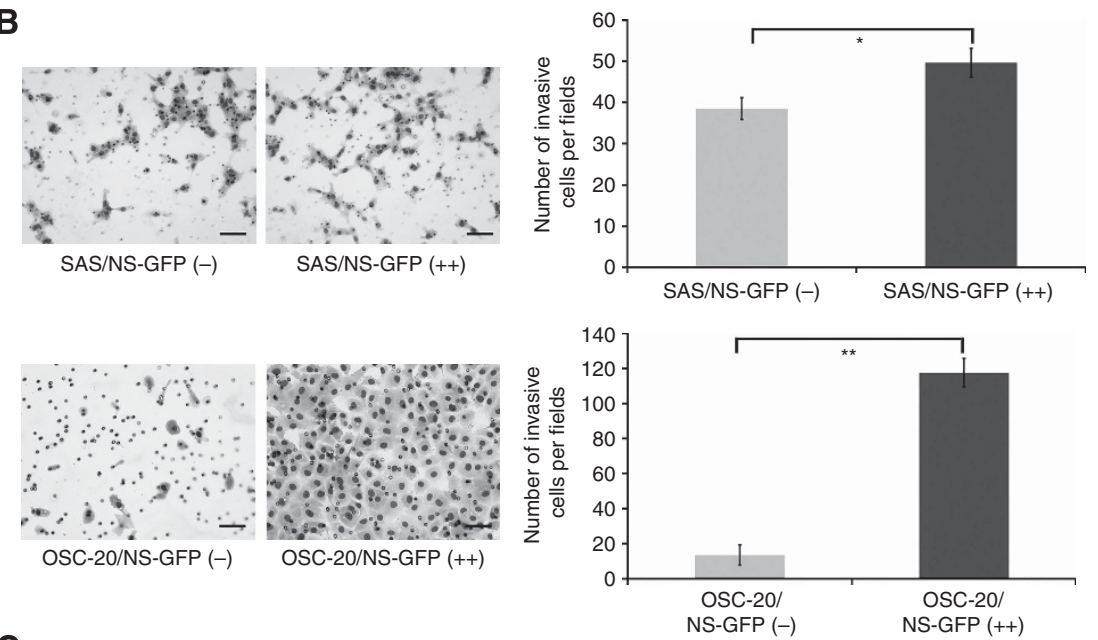

C
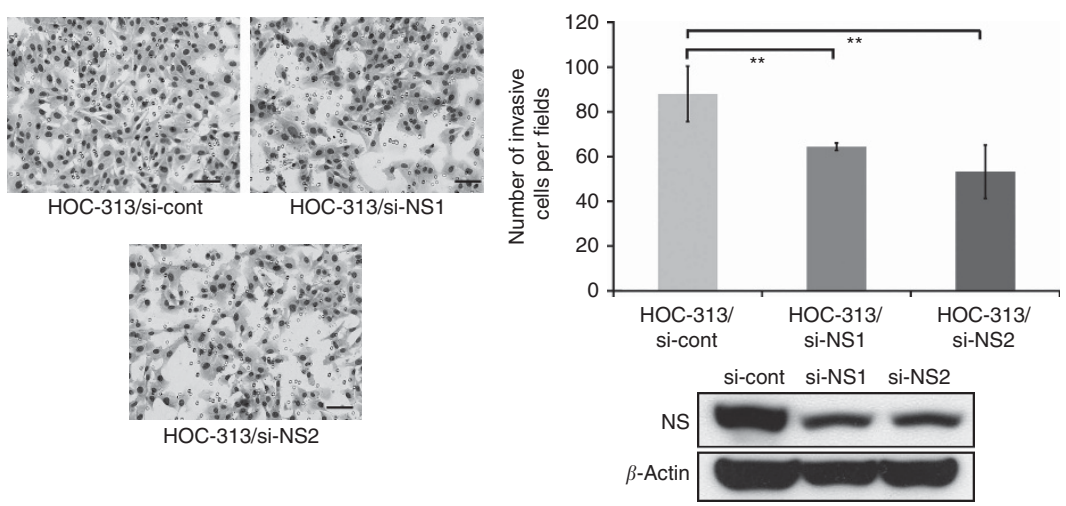

Figure 2. The expression level of NS affects the proliferation and invasion of OSCC cells. (A) The in vitro growth of the SAS and OSC-20 sublines. The proliferation of the cells in DMEM containing $10 \%$ FBS was monitored for 4 days. Bars: \pm s.d. of three individual experiments. ${ }^{\star} P<0.05$; ${ }^{\star \star} P<0.01$. (B) The results of an in vitro tumour invasion assay in cells with endogenous or overexpressed NS. Cells suspended in serum-free DMEM were seeded into the upper chamber with an $8-\mu \mathrm{m}$ pore size membrane coated with Matrigel. After $24 \mathrm{~h}$, the cells that had invaded to the bottom of the membrane in the outer chamber containing serum-supplemented DMEM were stained and quantified. A representative photograph of each group is shown. Original magnification, $\times 100$. Scale bars, $50 \mu \mathrm{m}$. The numbers of invaded cells obtained from three independent experiments were counted and statistically analysed. The values are expressed as the means \pm s.d. of triplicate samples. ${ }^{\star} P<0.05 ;{ }^{\star \star} P<0.01$, analysed by Student's t-test. (C) The results of the in vitro tumour invasion assay under NS knockdown conditions. Highly invasive HOC-313 cells were incubated with either control (cont) or NS-specific siRNA (si-NS1, si-NS2) for $24 \mathrm{~h}$. Then, cells suspended in serum-free DMEM were seeded into the upper chamber of a well containing an 8-mm pore size membrane coated with Matrigel. After $24 \mathrm{~h}$, the cells that had invaded to the bottom of the membrane in the outer chamber containing serum-supplemented DMEM were stained and quantified. A representative photograph of each group is shown. Original magnification, $\times 100$. Scale bars, $50 \mu \mathrm{m}$. The numbers of invaded cells obtained from three independent experiments were counted and statistically analysed. The values are expressed as the means \pm s.d. of triplicate samples. ${ }^{\star} P<0.01$, analysed by a one-way ANOVA with the Bonferroni/Dunn test. The effects of NS-specific siRNA on HIC-313 cells were confirmed by a western blot analysis.

kinds of cancers (Tamase et al, 2009; Lin et al, 2010; Okamoto et al, 2011). We previously reported that the downregulation of NS decreased the proliferation of OSCC cell lines in vitro (Yoshida et al, 2011). However, to the best of our knowledge, the effects of NS upregulation on cell proliferation have not yet been examined in OSCC. In the present study, we found that overexpression of NS increases the cell proliferation in two different OSCC cell lines (Figure 2A). Collectively, these data indicate that the tumour NS status regulates the proliferation of OSCC cells.
Recent studies have indicated that STAT3 has an important role in the progression of various cancers, such as stomach, breast and pancreatic cancer (Fukuda et al, 2011; Balanis et al, 2013; Wang et al, 2013). In pancreatic cancer, increased STAT3 signalling increases the expression of EMT-related molecules to induce invasion and metastasis (Fukuda et al, 2011). It had also been reported that overexpression of p-STAT3 was correlated with increased malignancy and a worse prognosis in patients with OSCC (Neiva et al, 2009; Shinriki et al, 2009; Macha et al, 2011). 
A

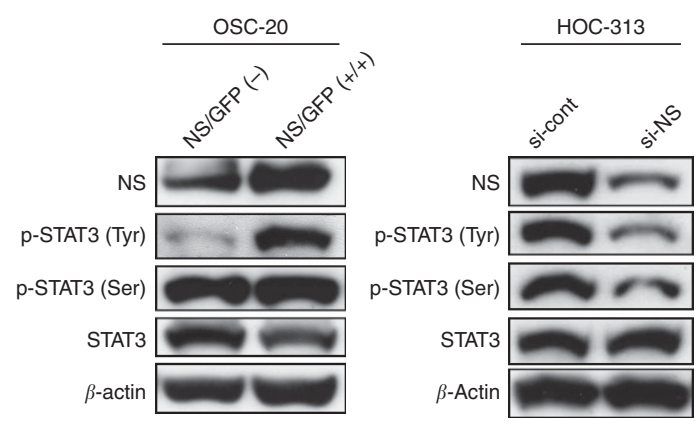

B

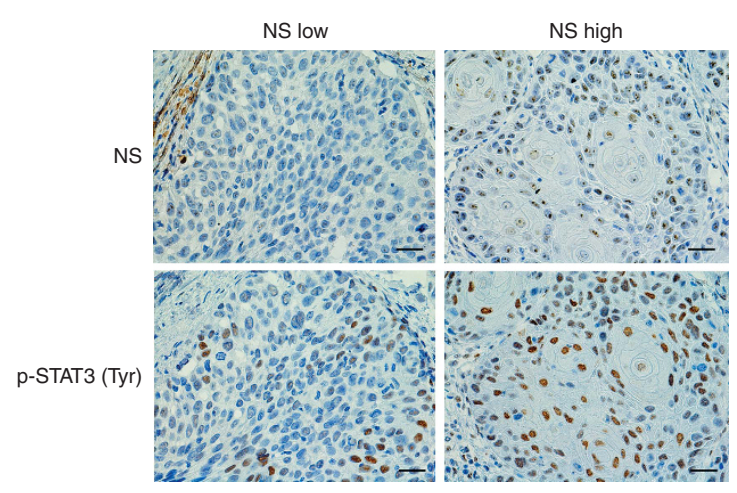

C
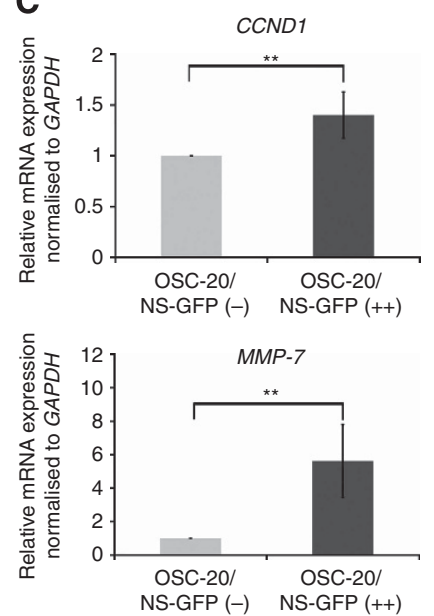
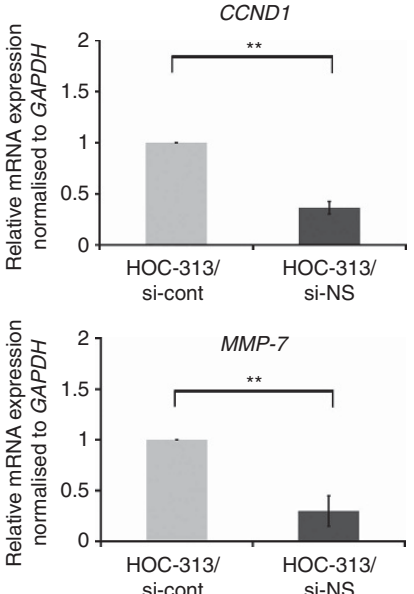

Figure 3. The expression levels of NS affect the activation of STAT3 and the expression of downstream targets. (A) The protein levels of NS, p-STAT3 (Tyr), p-STAT3 (Ser) and STAT3 in OSCC cells. OSC-20/ NS-GFP $(-)$ and GFP $(++)$ cells were harvested and protein samples were prepared, then each protein of interest was examined by a western blot analysis. HOC-313 cells were transfected with control (cont) or NS-specific siRNA (si-NS). At $48 \mathrm{~h}$ after transfection, the cells were collected and subjected to a western blot analysis. The expression levels of the indicated molecules were examined. (B) Representative immunohistochemical staining patterns of p-STAT3 (Tyr) in NS-low or high expressing OSCC tumours. The nuclear immunoreactions were regarded to indicate positive p-STAT3 (Tyr) staining. Scale bars, $100 \mu \mathrm{m}$. (C) The mRNA levels of downstream targets of the STAT3 signalling pathways in each cell line. The cells were harvested and the total RNA was extracted at the same time. The expression levels of CCND1 and MMP-7 were measured using QRT-PCR. The values are expressed as the means \pm s.d. of triplicate samples. The statistical analysis was performed using Student's t-test. ${ }^{\star \star} P<0.01$.

Okamoto et al (2011) reported that high NS-expressing cells exhibited increased phosphorylation of STAT3, and they suggested that this might lead to the aggressive malignant phenotypes. Together, these previous studies and our preset data (especially that

Table 1. Correlation between the nucleostemin expression status and clinicopathological factors in 54 OSCC patients

\begin{tabular}{|c|c|c|c|c|}
\hline \multirow[b]{2}{*}{ Variables } & \multicolumn{4}{|c|}{ Nucleostemin status } \\
\hline & $n$ & High & Low & $P$-value \\
\hline \multicolumn{5}{|l|}{ Age (years) } \\
\hline Median & 70.5 & 70.8 & 70 & \multirow{4}{*}{0.396} \\
\hline Range & $51-87$ & $51-82$ & $53-87$ & \\
\hline$\leqslant 65$ & 18 & $7(38.9)$ & $11(61.1)$ & \\
\hline$>65$ & 36 & $12(33.3)$ & $24(66.7)$ & \\
\hline \multicolumn{5}{|l|}{ Gender } \\
\hline Male & 31 & $12(38.7)$ & $19(61.3)$ & \multirow[t]{2}{*}{0.687} \\
\hline Female & 23 & 7 (30.4) & $16(69.6)$ & \\
\hline \multicolumn{5}{|l|}{ Primary site } \\
\hline Tongue & 13 & 5 (38.5) & $7(61.5)$ & \multirow[t]{4}{*}{0.585} \\
\hline Mandible & 10 & $4(40.0)$ & $6(60.0)$ & \\
\hline Maxilla & 12 & $3(25.0)$ & $9(75.0)$ & \\
\hline Oral floor & 9 & $2(22.2)$ & $8(77.8)$ & \\
\hline \multicolumn{5}{|l|}{ T-stage } \\
\hline $\mathrm{T} 1, \mathrm{~T} 2$ & 19 & $8(42.1)$ & $11(57.9)$ & \multirow[t]{3}{*}{$0.026^{\star}$} \\
\hline T3 & 18 & $2(5.3)$ & $16(94.7)$ & \\
\hline T4 & 17 & $9(52.9)$ & $8(47.1)$ & \\
\hline \multicolumn{5}{|l|}{$\mathrm{N}$-stage } \\
\hline N0, N1 & 31 & $7(22.6)$ & $24(77.4)$ & \multirow[t]{2}{*}{$0.024^{\star}$} \\
\hline$\geqslant N 2$ & 23 & $12(52.2)$ & $11(47.8)$ & \\
\hline \multicolumn{5}{|l|}{ Clinical stage } \\
\hline II & 4 & $1(25.0)$ & $3(75.0)$ & \multirow[t]{3}{*}{0.061} \\
\hline III & 19 & $4(21.1)$ & 15 (78.9) & \\
\hline IV & 31 & $14(45.2)$ & $16(54.8)$ & \\
\hline \multicolumn{5}{|c|}{ Differentiation } \\
\hline Well & 40 & $13(32.5)$ & $27(67.5)$ & \multirow[t]{2}{*}{0.485} \\
\hline Moderate & 14 & $6(42.9)$ & $8(57.1)$ & \\
\hline \multicolumn{5}{|c|}{ Pathological response } \\
\hline Grades 0, I, Ila & 12 & $6(50.0)$ & $6(50.0)$ & \multirow[t]{4}{*}{0.398} \\
\hline Grade Illb & 17 & $6(35.3)$ & $11(64.7)$ & \\
\hline Grade III & 8 & $1(12.5)$ & 7 (87.5) & \\
\hline Grade IV & 17 & $6(35.3)$ & $11(64.7)$ & \\
\hline \multicolumn{5}{|c|}{$\begin{array}{l}\text { Abbreviation: OSCC }=\text { oral squamous cell carcinoma. The chi-square test was used to } \\
\text { examine the relationships between nucleostemin expression and clinicopathological } \\
\text { factors. * } P<0.05 \text {. }\end{array}$} \\
\hline
\end{tabular}

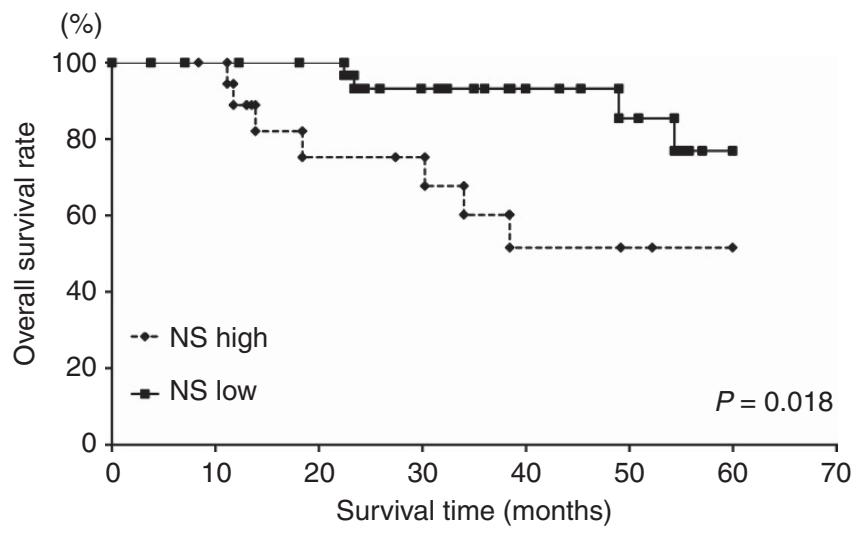

Figure 4. The overall survival of 54 OSCC patients based on their tumour NS status. ${ }^{\star \star} P<0.01$.

shown in Figure 3) support our conclusion that high NS expression contributes to malignant progression via the activation of the STAT3 signalling pathway in OSCC, thus leading to a poor prognosis in patients with OSCC.

To date, little is known about the biological properties of NS in OSCC. However, our functional study showed that NS-GFP 
Table 2. The results of a multivariate regression analysis for predicting the overall survival of 54 OSCC patients

\begin{tabular}{|l|c|c|c|c|}
\hline Variables & $\begin{array}{c}\text { Assigned } \\
\text { score }\end{array}$ & $\begin{array}{c}\text { Hazard } \\
\text { ratio }\end{array}$ & $95 \% \mathrm{Cl}$ & P-value \\
\hline T-stage & 1 & 0.55 & $-1.06-0.73$ & 0.656 \\
\hline T1, T2 & 2 & & & \\
T3 & 3 & & & \\
T4 & 0 & 0.46 & $-1.39-0.96$ & 0.656 \\
\hline N-stage & 1 & & & \\
N0 & 2 & & & \\
N1 & 3 & & & \\
N2b & N2c &
\end{tabular}

\section{Clinical stage}

\begin{tabular}{|l|l|l|l|l|}
\hline IIII & 1 & 0.47 & $-2.57-0.84$ & 0.363 \\
IV & 2 & & & \\
\hline Differentiation & 3 & & \\
\hline Well \\
Moderate & 0 & 0.68 & $-1.87-0.89$ & 0.562 \\
\hline
\end{tabular}

Pathological response

\begin{tabular}{|c|c|c|c|c|}
\hline $\begin{array}{l}\text { Grades 0, I, IIa } \\
\text { Grade IIb } \\
\text { Grade III } \\
\text { Grade IV }\end{array}$ & $\begin{array}{l}1 \\
2 \\
3 \\
4\end{array}$ & 0.73 & $-0.91-0.28$ & 0.295 \\
\hline \multicolumn{5}{|c|}{ Nucleostemin status } \\
\hline $\begin{array}{l}\text { Low expression } \\
\text { High expression }\end{array}$ & $\begin{array}{l}0 \\
1\end{array}$ & 9.09 & $0.78-3.83$ & $0.002^{*}$ \\
\hline
\end{tabular}

$(++)$ cells possess enhanced cell proliferation and invasion capacity. Recent studies showed that NS is involved in the regulation of the proliferation of stem cells ( $\mathrm{Qu}$ and Bishop, 2012; Meng et al, 2013; Yamashita et al, 2013), suggesting that NS may also be involved in tumour development by critically regulating cancer stem cells (CSCs). A major limitation of our study is that it remains unclear whether the malignant transformation caused by altered NS expression is owing to the modulation of a CSC population.

Our immunohistochemical analysis showed that high NS expression is associated with an advanced T-stage, nodal metastasis and a poor prognosis in patients with OSCC. Therefore, despite the potential clinical importance of NS, how CSCs are regulated by NS is unclear. On the other hand, in our preliminary data, NS-GFP $(++)$ cells showed an increased potential for sphere formation. Moreover, some genes that induce pluripotent stem cells (Takahashi and Yamanaka, 2006) were upregulated in these cells (data not shown). Therefore, NS-GFP $(++)$ cells seem to possess at least some of the properties of CSCs. The use of such cells in in vivo models may increase our understanding of the nature of CSCs.

In conclusion, our results demonstrate that NS may have an important role in the progression of malignant phenotypes in OSCC. Moreover, the overexpression of NS contributes to a poor prognosis in OSCC patients. Further studies will be needed to clarify the role of NS in OSCC and in CSCs, which may lead to the development of novel cancer therapies.

\section{ACKNOWLEDGEMENTS}

We thank Dr Atsushi Hirao for providing the pMY-NS-IRES-GFP vector, Dr Toshio Kitamura for providing Plat-E, Dr Etsuhide Yamamoto and Dr Shuichi Kawashiri for providing OSCC cell lines, and Mrs Motoko Kagayama, Mrs Takako Maeda and Mrs Hiroko
Kouzuma for their skilful technical assistance. We also thank Professor Brian Quinn for proofreading the manuscript. This work was supported by Ministry of Education, Culture, Sport, Science and Technology, Japan Grant-in-Aid for Research Activity Start-up (no. 24890173), Grant-in-Aid for Scientific Research (no. 23592967) and Grant-in-Aid for Scientific Research (no. 21590440).

\section{CONFLICT OF INTEREST}

The authors declare no conflict of interest.

\section{REFERENCES}

Balanis N, Wendt MK, Schiemann BJ, Wang Z, Schiemann WP, Carlin CR (2013) Epithelial to mesenchymal transition promotes breast cancer progression via a fibronectin-dependent STAT3 signaling pathway. J Biol Chem 288(25): 17954-17967.

Cada Z, Boucek J, Dvorankova B, Chovanec M, Plzak J, Kodets R, Betka J, Pinot GL, Gabius HJ, Smetana Jr. K (2007) Nucleostemin expression in squamous cell carcinoma of the head and neck. Anticancer Res 27(5A): 3279-3284.

Devarajan E, Huang S (2009) STAT3 as a central regulator of tumor metastases. Curr Mol Med 9(5): 626-633.

Fan Y, Liu Z, Zhao S, Lou F, Nilsson S, Ekman P, Xu D, Fang X (2006) Nucleostemin mRNA is expressed in both normal and malignant renal tissues. Br J Cancer 94(11): 1658-1662.

Fukuda A, Wang SC, JPt Morris, Folias AE, Liou A, Kim GE, Akira S, Boucher KM, Firpo MA, Mulvihill SJ, Hebrok M (2011) Stat3 and MMP7 contribute to pancreatic ductal adenocarcinoma initiation and progression. Cancer Cell 19(4): 441-455.

Gupta S, Kong W, Peng Y, Miao Q, Mackillop WJ (2009) Temporal trends in the incidence and survival of cancers of the upper aerodigestive tract in Ontario and the United States. Int J Cancer 125(9): 2159-2165.

Hanahan D, Weinberg RA (2011) Hallmarks of cancer: the next generation. Cell 144(5): 646-674.

Huang S (2007) Regulation of metastases by signal transducer and activator of transcription 3 signaling pathway: clinical implications. Clin Cancer Res 13(5): 1362-1366.

Laramore GE, Scott CB, Al-Sarraf M, Haselow RE, Ervin TJ, Wheeler R, Jacobs JR, Schuller DE, Gahbauer RA, Schwade JG, Campbell BH (1992) Adjuvant chemotherapy for resectable squamous cell carcinomas of the head and neck: report on Intergroup Study 0034. Int J Radiat Oncol Biol Phys 23(4): 705-713.

Lin T, Meng L, Li Y, Tsai RY (2010) Tumor-initiating function of nucleostemin-enriched mammary tumor cells. Cancer Res 70(22): 9444-9452.

Lin T, Meng L, Lin TC, Wu LJ, Pederson T, Tsai RY (2014) Nucleostemin and GNL3L exercise distinct functions in genome protection and ribosome synthesis, respectively. J Cell Sci 127(Pt 10): 2302-2312.

Macha MA, Matta A, Kaur J, Chauhan SS, Thakar A, Shukla NK, Gupta SD, Ralhan R (2011) Prognostic significance of nuclear pSTAT3 in oral cancer. Head Neck 33(4): 482-489.

Matsumoto K, Horikoshi M, Rikimaru K, Enomoto S (1989) A study of an in vitro model for invasion of oral squamous cell carcinoma. J Oral Pathol Med 18(9): 498-501.

Meng L, Hsu JK, Zhu Q, Lin T, Tsai RY (2011) Nucleostemin inhibits TRF1 dimerization and shortens its dynamic association with the telomere. J Cell Sci 124(Pt 21): 3706-3714.

Meng L, Lin T, Peng G, Hsu JK, Lee S, Lin SY, Tsai RY (2013) Nucleostemin deletion reveals an essential mechanism that maintains the genomic stability of stem and progenitor cells. Proc Natl Acad Sci USA 110(28): $11415-11420$

Nakajima TE, Yoshida H, Okamoto N, Nagashima K, Taniguchi H, Yamada Y, Shimoda T, Masutomi K (2012) Nucleostemin and TWIST as predictive markers for recurrence after neoadjuvant chemotherapy for esophageal carcinoma. Cancer Sci 103(2): 233-238.

Neiva KG, Zhang Z, Miyazawa M, Warner KA, Karl E, Nor JE (2009) Cross talk initiated by endothelial cells enhances migration and inhibits anoikis of squamous cell carcinoma cells through STAT3/Akt/ERK signaling. Neoplasia 11(6): 583-593. 
Okamoto N, Yasukawa M, Nguyen C, Kasim V, Maida Y, Possemato R, Shibata T, Ligon KL, Fukami K, Hahn WC, Masutomi K (2011) Maintenance of tumor initiating cells of defined genetic composition by nucleostemin. Proc Natl Acad Sci USA 108(51): 20388-20393.

Okumura K, Konishi A, Tanaka M, Kanazawa M, Kogawa K, Niitsu Y (1996) Establishment of high- and low-invasion clones derived for a human tongue squamous-cell carcinoma cell line SAS. J Cancer Res Clin Oncol 122(4): $243-248$.

Platz H, Fries R, Hudec M (1985) Retrospective DOSAK Study on carcinomas of the oral cavity: results and consequences. J Maxillofac Surg 13(4): 147-153.

Qu J, Bishop JM (2012) Nucleostemin maintains self-renewal of embryonic stem cells and promotes reprogramming of somatic cells to pluripotency. J Cell Biol 197(6): 731-745.

Romanova L, Grand A, Zhang L, Rayner S, Katoku-Kikyo N, Kellner S, Kikyo N (2009) Critical role of nucleostemin in pre-rRNA processing. J Biol Chem 284(8): 4968-4977.

Shimosato Y, Oboshi S, Baba K (1971) Histological evaluation of effects of radiotherapy and chemotherapy for carcinomas. Jpn J Clin Oncol 1(1): $19-35$.

Shinriki S, Jono H, Ota K, Ueda M, Kudo M, Ota T, Oike Y, Endo M, Ibusuki M, Hiraki A, Nakayama H, Yoshitake Y, Shinohara M, Ando Y (2009) Humanized anti-interleukin-6 receptor antibody suppresses tumor angiogenesis and in vivo growth of human oral squamous cell carcinoma. Clin Cancer Res 15(17): 5426-5434.

Siegel R, Naishadham D, Jemal A (2012) Cancer statistics, 2012. CA Cancer J Clin 62(1): 10-29.

Takahashi K, Yamanaka S (2006) Induction of pluripotent stem cells from mouse embryonic and adult fibroblast cultures by defined factors. Cell 126(4): 663-676.

Tamase A, Muraguchi T, Naka K, Tanaka S, Kinoshita M, Hoshii T, Ohmura M, Shugo H, Ooshio T, Nakada M, Sawamoto K, Onodera M, Matsumoto K,
Oshima M, Asano M, Saya H, Okano H, Suda T, Hamada J, Hirao A (2009) Identification of tumor-initiating cells in a highly aggressive brain tumor using promoter activity of nucleostemin. Proc Natl Acad Sci USA 106(40): 17163-17168.

Tsai RY, McKay RD (2002) A nucleolar mechanism controlling cell proliferation in stem cells and cancer cells. Genes Dev 16(23): 2991-3003.

Wang Z, Si X, Xu A, Meng X, Gao S, Qi Y, Zhu L, Li T, Li W, Dong L (2013) Activation of STAT3 in Human gastric cancer cells via interleukin (IL)-6-type cytokine signaling correlates with clinical implications. PLoS One 8(10): e75788.

Yamashita M, Nitta E, Nagamatsu G, Ikushima YM, Hosokawa K, Arai F, Suda T (2013) Nucleostemin is indispensable for the maintenance and genetic stability of hematopoietic stem cells. Biochem Biophys Res Commun 441(1): 196-201.

Yokoyama K, Kamata N, Hayashi E, Hoteiya T, Ueda N, Fujimoto R, Nagayama M (2001) Reverse correlation of E-cadherin and snail expression in oral squamous cell carcinoma cells in vitro. Oral Oncol 37(1): 65-71.

Yoshida R, Fujimoto T, Kudoh S, Nagata M, Nakayama H, Shinohara M, Ito T (2011) Nucleostemin affects the proliferation but not differentiation of oral squamous cell carcinoma cells. Cancer Sci 102(7): 1418-1423.

Zhu Q, Yasumoto H, Tsai RY (2006) Nucleostemin delays cellular senescence and negatively regulates TRF1 protein stability. Mol Cell Biol 26(24): 9279-9290.

This work is published under the standard license to publish agreement. After 12 months the work will become freely available and the license terms will switch to a Creative Commons AttributionNonCommercial-Share Alike 3.0 Unported License.

Supplementary Information accompanies this paper on British Journal of Cancer website (http://www.nature.com/bjc) 